\title{
Inovação em programas sociais: a introdução da TV Digital Interativa no Pro- grama Bolsa Família
}

\author{
Autores \\ Márcio Wohlers \\ Professor Associado \\ Instituto de Economia da UNICAMP \\ marcio.wohlers@gmail.com
}

\author{
Marcelo de Carvalho Pereira \\ Pós-Doutorando \\ Instituto de Economia da UNICAMP \\ marcelocpereira@uol.com.br
}

\begin{abstract}
Resumo
As desigualdades socioeconômicas no Brasil continuam bastante altas, não obstante as amplas políticas sociais, incluindo as transferências de renda propiciadas pelo Programa Bolsa Família (PBF) do Governo Federal. Desde seu início o PBF introduziu avanços tecnológicos e organizacionais significativos como o cartão magnético e o cadastro único. Em 2016 está previsto o lançamento de mais uma inovação: um terminal de TV digital interativa (TVDI) que permitirá o acesso a um amplo conjunto de informações para os milhões de inscritos no programa. Pela TVDI o beneficiário poderá fazer consultas sobre vagas de emprego, capacitação profissional, serviços públicos nas áreas de saúde, educação, segurança e transporte, além de serviços bancários, cursos técnicos e de educação financeira. A partir dos resultados do projeto piloto realizado em 2013 em uma comunidade de João Pessoa (PB), foi traçado um cenário visando identificar os principais impactos do projeto em sua nova fase. Para tanto, foi utilizado um modelo de simulação tipo agent-based, calibrado a partir da análise econométrica de dados primários da PNAD 2013. O modelo de simulação permite a comparação entre os domicílios com e sem TVDI, ao longo do tempo, por meio das variáveis econômicas mais relevantes, mesmo quando existe forte interação entre elas. Os resultados do modelo indicam efeitos modestos, mas relevantes, no nível dos domicílios individuais. Entretanto, no nível agregado os efeitos são bastante significativos, apesar de sugerirem a necessidade de integração desse tipo de iniciativa com um conjunto mais amplo de políticas sociais.
\end{abstract}

Palavras-chave: TV digital interativa, inclusão social, simulação agent-based, modelo econométrico, PNAD.

\begin{abstract}
Socioeconomic inequalities in Brazil remain very high, despite the broad social policies, including the cash transfers offered by the Bolsa Família Program (PBF) from the Federal Government. Since its inception the PBF introduced significant technological and organizational advances such as magnetic withdrawal card and the single database of supported citizens. In 2016 it is expected the launch of another innovation: an interactive digital TV terminal (TVDI) that allow access to a wide range of information subjects for the millions of subscribers in the program. TVDI allows the PBF beneficiary to make inquiries about jobs, job training, public services in health, education, security and transport, as well as banking, technical courses and financial education. From the results of the pilot project conducted in 2013 in a community at João Pessoa (PB), it was designed a model to identify the main impacts of the program in its new phase. For this, we used an agent-based simulation model, calibrated using econometric results from the microdata of PNAD 2013. The simulation model allows the comparison between households with and without TVDI, over time, through the most relevant economic variables, even when there is strong interaction between them. The model results indicate modest effects, despite relevant, at the level of individual households. However, at the aggregate level, the effects are quite significant, while suggesting the need for integration of this type of initiative with a broader set of social policies.
\end{abstract}

Keywords: interactive digital TV, social inclusion, agent-based simulation, econometric modeling, PNAD.

JEL Classification: L86, H53, C63, C21.

Área ANPEC: Economia Social e Demografia Econômica. 


\section{Introdução}

Este trabalho avalia o desdobramento, em larga escala, de uma experiência de política social direcionada a aumentar a inclusão social e digital por meio do acesso a aparelhos de TV digital interativa (TVDI). A presente análise é desdobramento de um projeto piloto de implantação de TVDI em domicílios de baixa renda, realizado no início de 2013. O objetivo é qualificar e, se possível, quantificar os efeitos econômicos dessa política de inclusão, na medida em que seja expandida para parcela significativa dos domicílios brasileiros semelhantes.

Durante o projeto piloto, aparelhos terminais de TV digital interativa, do tipo set top box $(\mathrm{STB})^{1}$, foram instalados em domicílios de uma comunidade de baixíssima renda na cidade de João Pessoa (Paraíba). Todos estavam inscritos no programa Bolsa Família do Governo Federal (PBF) e dispunham de aparelho de TV em cores. Foram oferecidos quatro aplicativos de TVDI para acesso a serviços governamentais: benefícios sociais do PBF, informações sobre empregos e cursos, informações sobre saúde e introdução à educação financeira. Os aplicativos oferecidos dispunham de funcionalidades adaptadas para indivíduos com elevado índice de analfabetismo funcional. O projeto começou a operar em janeiro de 2013 e, logo a seguir, foi realizada uma pesquisa de campo procurando avaliar junto aos usuários aspectos relevantes dos benefícios aportados pela TVDI (CASTILLEJO, 2013). Dentre as principais conclusões, ficou claro que os aplicativos referentes a direitos sociais e a oferta de cursos de qualificação e empregos foram os mais utilizados e que o uso dos aplicativos proporcionou uma importante redução de despesas para a obtenção de informações sobre os assuntos apresentados.

A Empresa Brasil de Comunicação (EBC), controlada pelo Governo Federal, conduziu o projeto piloto de João Pessoa e avalia estendê-lo para parcela substancial das famílias que participam do programa Bolsa Família em todo o país. O projeto piloto praticamente não contou com verbas públicas e seus custos foram arcados por empresas privadas, pesquisadores de universidades e recursos do Banco Mundial para contratação de consultores. Entretanto, a ampliação do projeto para uma escala significativa, considerando o número de domicílios que participam do PBF, exigiria recursos muito superiores. Com a licitação do radioespectro para a quarta geração $(4 \mathrm{G})$ da telefonia móvel, entretanto, a distribuição dos conversores de TV digital (TVD) para os beneficiários do PBF tornou-se uma obrigação das operadoras de telefonia, parcialmente equacionando a questão financeira. $^{2} \mathrm{O}$ adequado entendimento dos impactos econômicos, sociais e culturais de um empreendimento dessa magnitude é essencial para sua avaliação enquanto política pública.

Em um projeto de TVDI em larga escala, além dos serviços proporcionados pela disponibilização da internet nos domicílios - desde o simples correio eletrônico até sofisticadas versões da internet das coisas, há ainda o impacto de natureza mais geral da internet sobre o orçamento familiar e o crescimento econômico. Nesse sentido, um projeto de TVDI pode modificar algumas variáveis econômicas de grande alcance, tais como a produtividade, o nível de emprego e os custos de transações domiciliares. Esses efeitos, que aparentemente podem ser deflagrados por meio da massificação da TVDI, é o tema central pesquisado neste trabalho ${ }^{3}$. Mais especificamente, as implica-

\footnotetext{
${ }^{1} \mathrm{O}$ terminal de TVDI é um dispositivo conectado à internet, embora não possua todas as funcionalidades de um computador ou de um tablet. A conexão TVDI - internet representa o vínculo final de comunicação com o usuário e considera-se que seus efeitos são semelhantes aos da penetração da banda larga em uma região.

${ }^{2} \mathrm{O}$ terminal de TVD que será oferecido pelas operadoras não contém o hardware necessário para o canal de retorno, limitando a sua interatividade nativa. Entretanto, com pequeno custo adicional é possível adicionar a funcionalidade do canal de retorno, transformando-o em um terminal TVDI pleno.

${ }^{3}$ Este trabalho não avalia os aspectos tecnológicos da mudança do aparelho de TV analógico em TVDI.
} 
ções econômicas da utilização da TVDI de forma inclusiva nas comunidades brasileiras de baixíssima renda. Os efeitos econômicos específicos em questão, entretanto, são de naturezas distintas e constituem as duas perguntas chave deste trabalho, a saber: (i) qual o impacto econômico da massificação da TVDI nos domicílios de ínfimo rendimento, e (ii) qual é o subsídio necessário para viabilizar a TVDI, em particular o terminal interativo e os provedores de aplicativos (conteúdo)?

A avaliação do efeito econômico da massificação do projeto de TVDI requer a construção de um tipo de modelo que permita compreender os impactos, antes da implantação do projeto, bem como possa avaliar o grau de eficácia das políticas públicas propostas. Neste artigo, propomos a utilização de modelagem computacional por meio de simulação agent-based. Este tipo de modelo é conveniente em situações como esta, quando o grau de complexidade da situação modelada é significativo e a simplificação excessiva do modelo pode comprometer a resposta de questões relevantes. De forma simplificada, o modelo cria uma "sociedade virtual", na qual os agentes simulados são dotados de características e comportamentos semelhantes àqueles de seus congêneres no mundo real. Nessa modelagem, à semelhança da conduta verificada na pesquisa empírica primária (CASTILLEJO, 2013), os domicílios virtuais fazem uso dos aplicativos de TVDI para buscar informações e capacitação, tendo como objetivos reduzir suas despesas, conseguir emprego e aumentar sua renda, e para isso interagem com os provedores virtuais de aplicativos para TVDI. Estes agem de forma competitiva, inovando seus produtos de modo a oferecer melhores oportunidades de informação e capacitação para os domicílios, como forma de aumentarem suas parcelas de mercado e lucros.

A dinâmica do modelo de simulação proposto parte de duas hipóteses centrais: (i) a TVDI inclusiva tem efeitos econômicos diretos sobre os domicílios de baixa renda, de forma a aumentar a qualificação profissional, expandir a renda domiciliar e reduzir os custos para obtenção de informações sobre emprego e benefícios sociais; e (ii) o subsidio governamental é em princípio crítico, pois o mercado provavelmente não tem incentivos suficientes para deslanchar, por si, o programa de massificação da TVDI ou de outra solução alternativa de inclusão digital.

O artigo está organizado da seguinte forma: após esta introdução, o tópico 2 apresenta os principais conceitos teóricos necessários para interligar as premissas teóricas com a modelagem desenvolvida. O tópico 3, por sua vez, exibe os aspectos empíricos importantes utilizados na modelagem. O tópico 4 discorre sobre a especificação do modelo de simulação, inclusive as principais equações de suporte. Os resultados da simulação são examinados no tópico 5. A última parte apresenta as conclusões do trabalho.

\section{Aspectos teóricos}

Se no setor privado as inovações introduzidas, seja para criar um diferencial ou para melhorar a rentabilidade, requerem aceitação do mercado, no setor público é diferente. As inovações instituídas pelas autoridades responsáveis objetivam melhoria de atendimento ao púbico, eficiência, redução de custos e diversificação da oferta de produtos e serviços. Ou seja, apesar de alguns pontos em comum (como eficiência e diversificação), as diferenças no âmbito da inovação na espera pública são a ausência de busca de rentabilidade e a tomada de decisão por meio de uma autoridade.

A própria natureza de serviço público implica que o processo inovador obrigatoriamente leve em consideração as características sociais da população a ser atendida, como desigualdade de renda, escolaridade, saúde e envelhecimento. 
Grande parte da literatura desenvolvimento tecnológico e organizacional sobre a inovação nos serviços públicos faz parte de uma categoria mais ampla referente à inovação no setor de serviços em geral. Nas economias contemporâneas os serviços respondem por uma grande parte do PIB e do emprego e o setor é bastante diversificado em termos de tamanho, função e intensidade tecnológica. Quanto a este fator existem desde os KIBS (knowledge intensive business), segmentos intensivos em conhecimento e ligado a negócios, como áreas de informática, bancária e de telecomunicações, até os segmentos mais simples, como os serviços pessoais de beleza (manicure e cabeleireiro) que, em geral, utilizam mão de obra pouca qualificada e são de intensidade tecnológica muito baixa. Os serviços públicos e os programas sociais também são muito diversificados e, igualmente, apresentam intensidade tecnológica bastante diferenciada.

A literatura nacional e internacional é muito ampla, podendo ser destacados os estudos de Mulgan e Albury (2003), Harlvonsen et al. (2005) e Soraya B. e Bruno-Faria (2013). Os principais motivos para a introdução de inovações no setor público citados pelos três artigos acima são os seguintes:

- Surgimento de novos programas sociais: usualmente, a introdução de novos programas tende a usar novas tecnologias, sejam aquelas desenvolvidas de modo específico para o projeto, sejam as já existentes no mercado. No caso do PBF, a utilização de um Cadastro Único incluiu uma inovação do tipo organizacional (utilizando o cruzamento de dados com os coletados com a Pesquisa Nacional por Amostra de Domicílios - PNAD) e uma inovação de produto, representada pelo uso de cartão magnético por pessoas de baixo nível de instrução;

- Decisão dos dirigentes de políticas públicas: diante da necessidade de aperfeiçoar tecnologicamente os sistemas de produção do serviço (back-office) e de entrega (front-office), os responsáveis pelos projetos adotam medidas referentes à introdução de inovação que terão impactos positivos na eficiência e na eficácia do projeto. A introdução desse tipo de bem também implica na capacitação dos funcionários encarregados de sua operação;

- Compras públicas: o sistema de compras públicas por parte do governo é um mecanismo bastante conhecido. Não obstante a maioria das aquisições serem de bens e serviços comuns sem grande sofisticação tecnológica, existem importantes casos de licitação de bens de alta complexidade tecnológica, como no setor da saúde. ${ }^{4}$

As fontes para a adoção de melhorias tecnológicas e organizacionais abrangem não apenas aspectos internos ao programa (como maior eficiência), mas também a imitação devidamente adaptada de programas similares de outras instâncias públicas e mesmo em outros países.

As formas de introdução podem ser do tipo top-down ou botton-up (ALBURY; MULGAN, 2003). Conforme ressaltam os autores, no sistema top-down as inovações se originam em normas e instruções legais, enquanto que no modo botton-up a introdução da inovação é idealizada por técnicos de nível intermediário. Neste caso, usualmente as melhorias são testadas e introduzidas de for-

\footnotetext{
${ }^{4}$ Para uma análise mais aprofundada de compras tecnológicas no setor de saúde, consultar Albuquerque e Cassiolato (2002) e Viana e Silva (2010). Os dois últimos autores citam diversos aspectos críticos que influenciam o ritmo de difusão das tecnologias na saúde privada. E destacam os seguintes itens: (i) vantagem relativa da inovação, de acordo com a rentabilidade e sua importância social; (ii) canais de comunicação existentes (periódicos, congressos, feiras) sobre a oferta de novas tecnologias; (iii) regulamentação e redes sociais que impactam o ritmo de adoção de uma inovação; (iv) infraestrutura física e de trabalhadores qualificados necessários à introdução e uso da inovação e (v) compatibilidade com as tecnologias e padrões sociais já existentes. À exceção do item de busca de rentabilidade, os demais fatores são similares para o sistema público de saúde.
} 
ma experimental, em pequena escala. Sua difusão, em larga escala, somente ocorre após a devida sanção dos dirigentes do programa.

Há também a possibilidade da introdução das inovações ser obstruída. Dentre os diversos motivos para esse bloqueio, o mais importante refere-se à inexistência de recursos destinados para as mudanças. Outros motivos são: aversão ao risco por parte dos dirigentes, inexistência de técnicos habilitados, falta de incentivos e ausência de redes de inovação envolvendo programas similares dentro e fora do país. 5,6

Além das obstruções indicadas acima, que podem ser consideradas como internas ao projeto, pode-se ressaltar também a existência de bloqueios de natureza externa. Eles costumam ser de ordem política e não se restringem às mudanças tecnológicas, mas ainda à adoção e ao perfil dos programas e políticas sociais.

No caso brasileiro, Fagnani (2014) aponta a existência de duas correntes políticas com visões distintas das políticas sociais: a corrente liberal e o projeto social-desenvolvimentista.

A visão liberal ressalta que a política social deve focar no contingente mais pobre da população. As demais políticas sociais, voltadas ao crescimento, melhoria quantitativa e qualitativa do emprego, aumento do salário mínimo e as políticas universais, como saúde e educação, são consideradas inadequadas para combater a pobreza. Ou seja, a distribuição de renda é considerada uma medida correta, desde que a inclusão social ocorra na margem do sistema socioeconômico e não no seu centro. Essa visão também considera que a política social não integra a estratégia macroeconômica nacional.

Por sua vez, a linha social-desenvolvimentista crê que a política social não deve incidir somente nas camadas de baixa renda, e sim universalizar os direitos do cidadão (FAGNANI, 2014). As ações referentes à distribuição de renda, redução das desigualdades sociais, elevação do consumo das famílias e aumento da mobilidade social são de importância decisiva e devem fazer parte da política macroeconômica. Ou seja, essa política implica a efetivação do gasto público como um componente de grande importância na demanda agregada de modo a permitir uma ampliação da distribuição pessoal, funcional e regional da renda (CASTRO, 2012). Em termos mais amplos, as ações sociais devem estar alinhadas com mudanças estruturais na economia, em que são adicionados novos blocos produtivos com maior produtividade (eficiência schumpeteriana) e nos setores em alta expansão doméstica e externa (eficiência keynesiana) (CEPAL, 2012).

À medida que a economia cresce com base nos setores "não commodities" e de alta produtividade, haverá espaço para o aumento do gasto público de natureza social e consequentemente o maior volume de gastos propicia a introdução de inovações. De maneira inversa, a redução de gastos sociais diminui a possibilidade de melhorias tecnológicas e organizacionais.

A visão social-desenvolvimentista constata que, não obstante a importância da universalização dos direitos da cidadania, existe um problema histórico-estrutural de desigualdade que advém da não correção das distorções, de base escravista, da economia brasileira. A superação dos problemas estruturais exige uma mudança nos padrões de apropriação e distribuição de renda e riqueza

\footnotetext{
${ }^{5}$ INNO GRIPS (2010) apresenta uma ampla listagem dos obstáculos para a introdução de inovações, ocorridas período 1990 - 1998, nos Estados Unidos.

${ }^{6}$ Rausseret et al. (2011) analisam o processo mais geral de formulação e implementação de políticas públicas. A análise realizada pelos autores no âmbito da implementação inclui variáveis que interessam à introdução de melhorias tecnológicas em políticas sociais. Conforme descrito no capítulo introdutório, os fatores a serem considerados são: (i) formação de grupos de interesse e de coalizões políticas; (ii) sistema de incentivos; (iii) comportamento estratégico do setor privado e da burocracia pública e (iv) credibilidade das políticas implementadas.
} 
A distinção entre as duas correntes abrange igualmente o modo de provisão dos serviços públicos. A corrente liberal propõe uma oferta mercantil (privada) dos serviços sociais, como saúde, previdência educação, transportes, segurança e outros de natureza pública, enquanto que a socialdesenvolvimentista apoia a oferta pública desses serviços, devidamente financiados por impostos e gastos previdenciários públicos. Vale ressaltar que essas duas visões sempre estiveram presentes na discussão política e econômica brasileira dos últimos 50 anos, sempre disputando espaço político (e fiscal) (MEDEIROS, 2015). Enquanto que na década de 1990, nos governos Fernando Collor e Fernando Henrique Cardoso, houve um predomínio relativos da visão liberal, a partir do primeiro governo Lula, em 2003, há uma reversão das posições relativas (FAGNANI, 2005).

A inovação em programas sociais, foco deste trabalho, trata da disponibilização de informações aos inscritos no PBF através da TVDI. A inovação está na oferta de novos serviços que está sendo introduzida por dirigentes do programa. A operacionalização se dará em conjunto com outros órgãos, especialmente os ministérios das Comunicações e da Educação. O conteúdo de informações ofertadas ajudará o beneficiário a identificar, por exemplo, cursos de qualificação ou programas ligados à saúde, que, por sua vez, facilitarão o cumprimento das condicionalidades do $\mathrm{PBF}^{7}$.

Outro aspecto a ser examinado neste tópico destaca brevemente o impacto das TICs sobre o crescimento econômico e o bem-estar dos domicílios, destacando as relações de causalidade sugeridas.

No plano econômico, o primeiro impacto relevante das TICs refere-se aos ganhos de produtividade que ocorrem ao nível microeconômico, seja em relação aos indivíduos e domicílios, seja em relação às empresas ${ }^{8}$. Vale ressaltar que a simples presença das TICs, e da internet em particular, é insuficiente para a alteração da produtividade desses agentes. É necessária ainda a presença dos equipamentos de TI e a realização de mudanças culturais e organizacionais que abram espaço econômico para as alterações produtivas e as novas formas de interações entre os distintos recursos e atividades dos agentes econômicos. Além disso, deve ser sublinhado que o impacto das TICs no crescimento apresenta normalmente a forma de uma curva do tipo "U" invertido. Nessa curva existe: (i) um ponto de "massa crítica", situado acima da metade da parte crescente do "U" invertido (retornos crescentes de escala), a partir do qual os efeitos (como as fortes externalidades de rede) começam a operar; (ii) um ponto de saturação, no máximo do "U" invertido; (iii) em seguida do ponto de máximo, tem inicio a parte decrescente, onde há retornos decrescentes de escala. Por sua vez, os investimentos em infraestrutura e equipamentos de TIC demandam a contratação de empregados para instalar a respectiva infraestrutura (efeitos diretos). Dessa forma, geram multiplicadores de emprego, diretos e indiretos, aumentam a renda familiar e estimulam o crescimento econômico.

Como pode ser visto na Figura 1, observa-se que à medida que as sociedades se desenvolvem, aumenta a densidade do tecido produtivo e seus processos de produção tornam-se mais complexos, de forma a demandar um aumento dos chamados "trabalhadores da informação" (que coletam, processam e analisam dados e informações). A maior presença desses trabalhadores aumenta a velocidade de processamento das informações e provoca um incremento da produtividade. $O$ processo de desenvolvimento, portanto, implica em um número crescente de "trabalhadores da informação", os

\footnotetext{
${ }^{7}$ No que se refere à condicionalidade da educação, a introdução da TVDI está diretamente associada ao aumento da alfabetização digital, item imprescindível para a inserção no mercado de trabalho da sociedade contemporânea.

${ }^{8}$ No sentido de investigar o impacto das TICs no crescimento, atualmente existem três metodologias principais: (i) a contabilidade do crescimento (growth accounting); (ii) os estudos na linha do economista Robert Barro, que endogenizam o progresso técnico e recorrem extensivamente a modelos econométricos, relacionando variáveis TICs com o crescimento; e (iii) os estudos de natureza microeconômica e setorial, com uso selecionado de exames econométricos. Este trabalho segue a última abordagem, sublinhando as relações de causalidade existentes.
} 
quais, nas sociedades contemporâneas, somente podem ser devidamente qualificados na medida em que exista um setor de $\mathrm{TIC}^{9}$ (produtor ou importador de bens e serviços de TIC). Essa segunda "rodada" do aumento de "trabalhadores da informação" leva igualmente à um aumento da produtividade das firmas e dos trabalhadores. Na realidade, trata-se de um processo de realimentação, pois o crescimento constante do número de trabalhadores especializados contribui para a maior complexidade do processo produtivo, requerendo uma elevação na quantidade de especialistas em TICs ("trabalhadores da informação"). Esses efeitos refletem a presença das externalidades de rede ${ }^{10}$ (KATZ, 2009).

Figura 1 - Impactos econômicos das TICs: relações de causalidade.

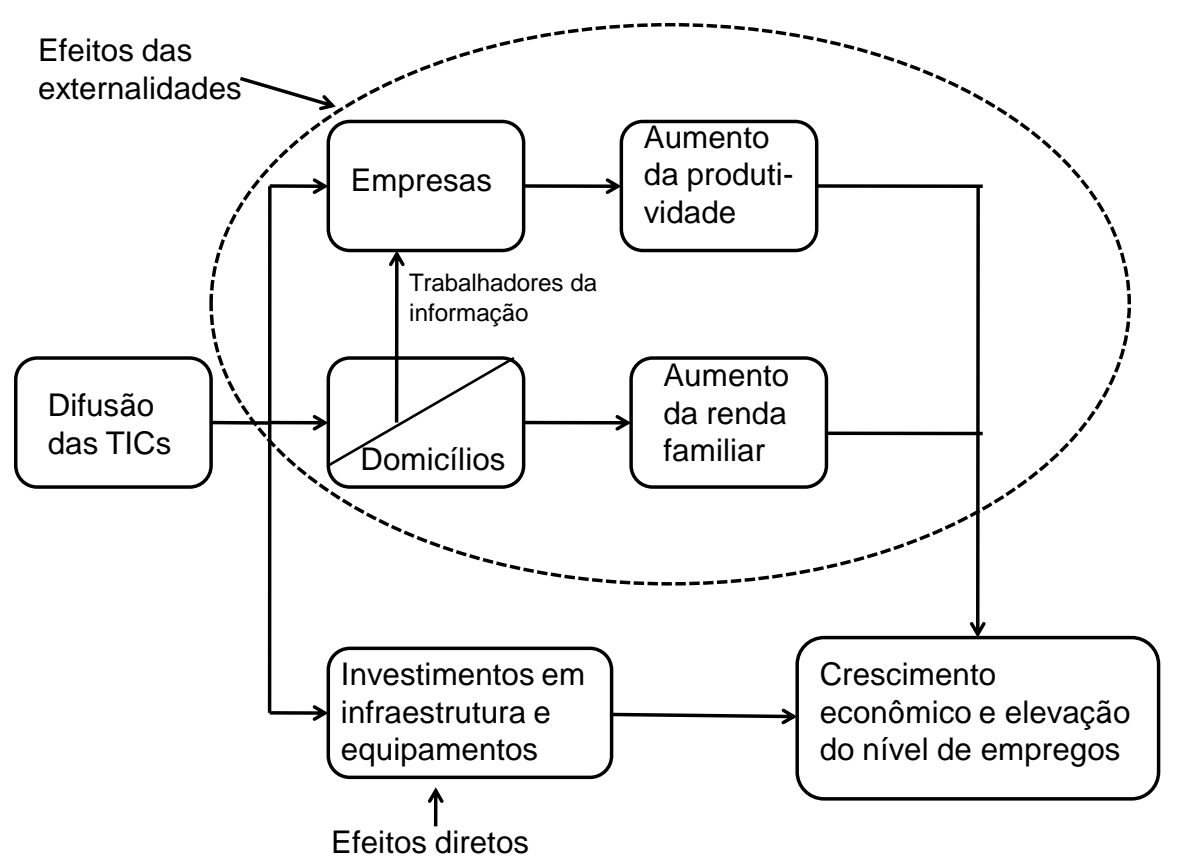

FONTE: ITU (2012).

O segundo efeito econômico das TICs refere-se à diminuição dos custos de transação ${ }^{11}$. De forma bastante abreviada, deve ser sublinhado que esses custos representam despesas incorridas por um agente econômico (indivíduo, domicílio, firma etc.) para a aquisição de produtos, serviços e informações por meio do mercado. No caso das empresas, exemplos comuns de custos de transação são aqueles referentes à escolha e manutenção do fornecedor mais apto e capacitado, ao estabelecimento de contratos adequados e à resolução de conflitos. Ademais, deve ser lembrado que os custos de transação estão no cerne da conhecida questão do "make or buy", produzir internamente ou utilizar-se do mercado como fonte dos insumos. Ao recorrerem ao mercado, com o auxílio das TICs, os

\footnotetext{
${ }^{9} \mathrm{Na}$ figura 1, não está representado o setor de produtos de TICs.

${ }^{10}$ Deve ser acrescentado que há um efeito induzido referente à geração do excedente do consumidor. Esse conceito deve ser entendido nos marcos da teoria econômica neoclássica. Na medida em que o preço de mercado for constante e a curva de demanda decrescente, pode-se dizer que o consumidor estaria disposto a comprar uma parcela desses bens por preços superiores aos de mercado, o que daria origem ao excedente do consumidor.

${ }^{11}$ Do ponto de vista teórico, os custos de transação fazem parte de uma ampla e profunda discussão analítica, envolvendo economia, administração e direito. Os artigos e livros seminais sobre o tema começaram em 1937, quando Ronald Coase (1937) publicou o clássico artigo "The Nature of the Firm". A continuidade temática ocorreu de forma mais ampla a partir da década de 1970. Nesse aspecto, deve ser ressaltada a obra de Oliver Williamson (1985).
} 
agentes podem obter a redução de importantes custos de transação ${ }^{12}$, elevando a eficiência das empresas e reduzindo as despesas de indivíduos e domicílios.

A navegação na internet, diretamente ou mediada por aplicativos específicos, facilita amplamente a realização das transações, uma vez que impõe padrões eficientes de informação, de busca e de pesquisa, com custos frequentemente irrisórios (em especial diante do modelo de negócios financiados por publicidade). Enfim, as transações realizadas por meio eletrônico, sejam no nível puramente comercial (e-commerce), como governamental (e-government) ou mesmo educacional $(e-$ learning), promovem uma substancial redução dos custos de transação, aumentando sensivelmente a produtividade dos agentes ${ }^{13}$ envolvidos.

Vale ainda recordar que a internet não é acessada pelos seus usuários apenas por meio de cabos ou de forma wireless. A digitalização da transmissão da radiodifusão terrestre, que propicia a operação da TV digital (TVD), oferece também um novo canal para a utilização da internet. Quando equipada com canal de retorno, equipamentos terminais e a plataforma de rede apropriados, a TVD permite o acesso interativo à internet. Note-se, entretanto, que na medida em que o sistema da TVD foi originalmente desenhado para a transmissão de sons e imagens, ressaltamos que não estão presentes algumas funcionalidades usuais dos sistemas operacionais dos equipamentos de acesso fixos (computador) ou móveis (tablet e smartphone). Dessa forma, a TVDI integra o conjunto de soluções para a chamada "última milha" da rede de telecomunicações e, no Brasil, faz parte do denominado Plano Nacional de Banda Larga, que integra, entre outras, um amplo leque de políticas de inovação, comunicação, inclusão e educação através da internet.

Por fim, deve-se ressaltar que há bastante tempo foi detectada a correlação positiva entre educação e renda. As agências internacionais, como o Banco Mundial (1995), vêm consolidando esse conhecimento desde a década de 1990. Entretanto, em países com altos níveis de desigualdade ${ }^{14}$, como Brasil e países latino americanos, a associação entre educação e renda precisa ser aprimorada, de modo a incluir duas questões adicionais: o ciclo generacional da pobreza ${ }^{15}$ e os recursos necessários para formação do capital cognitivo, que incorpora conhecimento e inovação ${ }^{16}$. Isso indica que, para operar também para as camadas mais pobres da população, a teoria do capital humano necessita ainda do funcionamento de serviços sociais de qualidade.

\footnotetext{
${ }^{12}$ Vale também ressaltar que existe um tópico bastante interessante e praticamente consensual entre os especialistas: a identificação dos custos de transação é normalmente uma operação relativamente simples, ao passo que sua mensuração costuma ser uma tarefa difícil, ou mesmo impossível.

${ }^{13}$ Também no caso do envolvimento direto de um individuo ou domicílio, efetuando negociações por meio das TICs, a internet representa um extraordinário facilitador (enabler) das transações, aumentando sua eficiência.

${ }^{14}$ Para autores como Cimoli (2005, p. 7), a desigualdade também apresenta um componente denominado heterogeneidade estrutural que constitui "um novo padrão em que não apenas predominam as diferenças de produtividade inter e intrasetoriais, mas também as diferenças quanto à capacidade de gerar e difundir a mudança tecnológica nos agentes econômicos".

${ }^{15} \mathrm{O}$ rompimento da influência da pobreza generacional sobre a renda ocorre com a educação precoce, mas de qualidade, para que os filhos de pais pobres passem a ter novas oportunidades no futuro, afastando o risco da perpetuação da pobreza. Ao mesmo tempo, esses mesmos filhos precisam ter acesso a bens públicos essenciais, como saúde e educação, de nível adequado.

${ }^{16} \mathrm{~A}$ aquisição do capital cognitivo exige o acesso a centros de treinamento, pesquisa desenvolvimento, além de qualidade de vida apropriada. Isso significa acesso a cultura, línguas estrangeiras, lazer etc., como pré-requisito para poder tomar parte das redes nacionais e internacionais de conhecimento.
} 


\section{Aspectos empíricos}

Durante o projeto piloto de TVDI em João Pessoa, foram instalados conversores digitais do tipo set top box (STB), que transformam as TVs analógicas convencionais em TVs digitais interativas (TVDIs), nas residências de cerca de 100 famílias de baixíssima renda participantes do programa Bolsa Família (PBF), no início de 2013. Como destacado na introdução, a Empresa Brasil de Comunicação (EBC) transmitiu, por meio do canal de serviços (canal 61), quatro aplicativos: benefícios sociais do PBF, emprego e cursos, saúde e educação financeira. Os aplicativos foram funcionalmente desenhados para o perfil de usuário em questão: indivíduos excluídos social, econômica, cultural e/ou digitalmente, predominantemente analfabetos de tipo funcional. Portanto, os aplicativos oferecidos recorriam extensivamente a vídeos e ícones e utilizavam pouco texto. $\mathrm{O}$ aparelho TV foi selecionado como terminal por ser equipamento presente em $98 \%$ dos domicílios brasileiros e cujo manuseio é dominado pelas famílias de baixa renda ${ }^{17}$.

O enfoque da plataforma de dois lados (Evans, 2011) é bastante útil para examinar a TVDI, como utilizada no projeto piloto. Ressalte-se, mais uma vez, que a natureza do projeto foi de empreendimento social e de política pública. Esse enfoque permite, por exemplo, distinguir as estratégias e evolução de ambos os lados. No caso do "lado" representado pelos domicílios de baixíssima renda, pode ser examinado o comportamento referente ao impacto dos aplicativos na conduta dos agentes, em particular a motivação, o correto entendimento dos aplicativos, a facilidade do uso, a utilidade das informações e a relevância do conhecimento obtido. Diante dessas informações, o lado dos "provedores de aplicativos" pode desenvolver sua estratégia de evolução, bem como definir a natureza dos aplicativos a serem disponibilizados, permitindo ainda verificar e modificar continuamente suas estratégias. Em particular, a plataforma pode ajudar a definir formas mais efetivas de inclusão social e digital ${ }^{18}$.

No caso da motivação referente ao uso dos aplicativos, cerca de $20 \%$ dos entrevistados não utilizou nenhum aplicativo, talvez porque não tivesse interesse ou estivesse receoso em relação ao seu uso. Considerando aqueles usuários que utilizaram os aplicativos uma, duas, três ou quatro ou mais vezes, as frequências de utilização foram próximas; respectivamente representaram 15\%, 20\%, $25 \%$ e $19 \%$ do total. Na medida em que $65 \%$ usaram os aplicativos mais de uma vez, pode-se supor que sua avaliação deva ter sido positiva. Parece, portanto, razoável conjeturar que, caso mais aplicativos adequados estivessem disponíveis, provavelmente eles seriam utilizados.

\footnotetext{
${ }^{17}$ Entretanto, existem muitas barreiras para a inclusão digital: disponibilidade de acesso; usabilidade e acessibilidade; inteligibilidade; fruição de conteúdos; criação de conteúdos (inclusão digital plena), conforme Holanda (2007). As duas primeiras barreiras são intrinsecamente superadas pela TVDI. As barreiras do terceiro tipo, de alta intensidade, como a limitação cognitiva, a ausência de níveis educacionais apropriados (analfabetismo funcional), a ausência de uma linguagem ajustada ao tipo de público, pode ser apenas parcialmente superada por melhorias progressivas do conteúdo oferecido pela TVDI. A superação plena desses limites, entretanto, depende de formação educacional mínima adequada.

${ }^{18}$ De forma mais ampla, o conjunto da plataforma representa o que é denominado na literatura por "Sistema Setorial de Inovação" (SSI) (MALERBA; ORSENIGO, 2000). O termo sistema indica a existência de uma rede de instituições públicas e privadas, cuja permanente interação "inicia, importa, modifica e difunde novas tecnologias" (OECD, 1997). No mínimo, existem três diferentes tipos de instituições envolvidas: (a) universidades e centros de pesquisa, tecnologia e desenvolvimento; (b) setor público, englobando órgãos que definem e programam políticas publicas, financiam e promovem o funcionamento do sistema; e (c) empresas privadas ou públicas que absorvem/expandem a tecnologia desenvolvida e ofertam os novos produtos no mercado. No caso do projeto, podemos enumerar as organizações envolvidas (com o risco de omitir algumas instituições): (a) Lavid, PUC-RJ, rede pesquisadores constituídos a partir de 1995 por meio de chamada publica da Finep, os quais, entre outras inovações desenvolveram o middleware Ginga; (b) EBC, segmentos ligados à Presidência da Republica, Ministério das Comunicações e BNDES (criou em 1997 o ProTVD (Programa de Apoio à Implementação do SBTVT); e (c) TOTVS, D-Link e demais fabricantes de STBs ou suas partes. O SSI-TVDI ainda é relativamente pequeno, mas encontra-se em expansão.
} 
Aparentemente, devido ao adequado uso de vídeos, cores, ícones e caracteres, o correto entendimento dos aplicativos foi exitoso. As avaliações positivas, para cada um dos aplicativos disponibilizados parecem confirmar esse fato. A interface foi entendida como amigável, para cada aplicativo, pelas seguintes proporções de usuários: $81 \%$ para o aplicativo de empregos e cursos, $79 \%$ no de saúde, $79 \%$ em benefícios sociais e $47 \%$ para o aplicativo de educação financeira.

No que se refere à utilidade das informações, o questionário previa quatro respostas: "nenhuma", "pouca", "satisfatória" ou "muita". Agregando-se as respostas do tipo "satisfatória" e "muita", a classificação foi a seguinte: (i) a informação sobre melhoria da qualificação profissional obteve $100 \%$ de utilidade, (ii) a informação referente à busca de emprego foi classificada como útil por $89 \%$, e (iii) a informação sobre benefícios sociais foi considerada como útil por $83 \%$. Finalmente, os usuários foram questionados sobre a aplicação do conhecimento obtido: (i) para 64\%, a utilização concentrou-se na redução de despesas para obter informações; (ii) 27\% não responderam; (iii) $7 \%$ disseram que não houve aplicação; e (iv) $2 \%$ informaram que obtiveram um emprego com o apoio do respectivo aplicativo.

\section{Especificação do modelo}

O modelo de simulação proposto tem por objetivo avaliar os efeitos econômicos decorrentes da implantação em larga escala da TVDI, para um segmento específico dos domicílios brasileiros: os participantes do PBF. Isso é especialmente relevante considerando-se a distribuição gratuita de STB para esses domicílios ${ }^{19}$, durante o processo de desligamento da rede de televisão analógica (TVA) e sua migração para o sistema digital (TVD) (MINICOM, 2014). A utilização de um modelo de simulação permite avançar além do que seria em princípio factível com os métodos de avaliação mais usuais, como modelos de estática comparativa ou mesmo planilhas de cálculo sofisticadas. Ao modelar individualmente os agentes envolvidos no processo econômico em questão, a simulação permite apreciar, de forma detalhada, tanto a dinâmica temporal do sistema modelado como os efeitos micro e macroscópicos das interações entre agentes heterogêneos (COLANDER, 2005). A obtenção desse nível de informação, sem o recurso da simulação, não é em geral factível, exceto para os casos mais simples. Por outro lado, o modelo de simulação, como qualquer modelo, é apenas uma ferramenta auxiliar do processo analítico; por si, ele não é capaz de propor hipóteses explanatórias ou, em termos mais gerais, de ir além do escopo do quadro teórico utilizado na sua construção (AXELROD; TESFATSION, 2006).

O modelo foi especificado para estudar os benefícios econômicos decorrentes da introdução da TVDI e seus aplicativos nesse conjunto de domicílios. Duas categorias de benefícios serão investigadas: os diretos e os indiretos. Por benefícios diretos entendemos aqueles que resultam de reduções das despesas domiciliares (custos de transação), advindas diretamente da utilização dos aplicativos, como por exemplo, economias com deslocamento urbano, telefonia e tempo de trabalho (custo de oportunidade) para a busca de informações sobre emprego, qualificação profissional e benefícios sociais. Na categoria dos benefícios indiretos, buscamos explorar os impactos do uso de aplicativos da TVDI sobre os rendimentos (oriundos do trabalho) do domicílio, o nível de qualificação profissional, a facilidade de encontrar emprego e os tempos de procura e de permanência nos empregos.

\footnotetext{
${ }^{19}$ Apesar de a distribuição do STB básico para a TVD ser gratuita, a utilização da TVDI requer ainda a adição de um modem e a contratação de serviço de telecomunicações para a implementar o canal de retorno, já que o sistema de TVD, como implantado no Brasil, não prevê essa facilidade utilizando-se seu próprio radioespectro.
} 
Obviamente, seria desnecessária a utilização de modelos de simulação para a análise tão somente dos benefícios diretos acima descritos. As relações de causa e efeito, nesse caso, são suficientemente simples para serem investigadas utilizando-se modelos tradicionais. Entretanto, o mesmo não acontece no caso dos benefícios indiretos. A interação entre as diversas variáveis envolvidas (rendimentos do trabalho, qualificação profissional, nível de desemprego, "estoques" de empregados/desempregados, tempos de busca e permanência no emprego), em um ambiente de agentes heterogêneos, é suficientemente complexa para gerar padrões difíceis de serem plenamente avaliados por meio de modelos de equilíbrio convencionais, em particular considerando-se o longo período de implantação previsto neste caso.

A especificação do modelo proposto se baseia em dois tipos de interações distintas: entre domicílios e provedores de aplicativos de informação - por meio da plataforma da TVDI - e dos domicílios no mercado de trabalho (onde os benefícios indiretos são auferidos). Os agentes do tipo "provedor" (oferta de aplicativos) e "domicílio" (demanda por aplicativos e oferta de trabalho) e serão modelados individualmente, por meio de agentes heterogêneos ${ }^{20}$, enquanto a demanda por trabalho será representada de forma "monolítica", ou seja, como um demandante único e homogêneo $^{21}$. O comportamento dos agentes será descrito por equações em diferenças, adequadas para configuração do sistema de simulação informatizado adotado.

O modelo especificado contém 13 equações principais - que partem das premissas teóricas explicitamente assumidas para modelar variáveis de estado que caracterizam o comportamento dos agentes $^{22}$. As equações em diferenças da especificação dependem, ainda, da definição de 17 parâmetros. Para simplificar o processo de escolha dos parâmetros ("calibração"), optou-se por modelagem que permitisse o maior uso possível da informação empírica disponível sobre o tema. O Apêndice apresenta em detalhes as características técnicas do modelo, as variáveis e parâmetros, os valores de calibração e a origem dos dados empíricos. Em resumo, 13 parâmetros foram ajustados a partir da informação disponível e 4 de modo arbitrário. Destes, apenas um deles é crítico para os resultados produzidos pelo modelo, sendo que algumas das possíveis configurações ("cenários") foram testadas e serão apresentadas na próxima seção.

A simulação segue uma sequência lógica, em cada unidade de tempo simulada (time step): (i) conforme a implantação do sistema TVDI avançam na "sociedade virtual", os domicílios recebem (ou não) um STB (set top box); (ii) os domicílios escolhem periodicamente um provedor de aplicativo de boa qualidade; (iii) os domicílios com chefe desempregado ${ }^{23}$ decidem se usam ou não o aplicativo de qualificação profissional e, em caso positivo, incrementam sua qualificação; (iii) os domicílios com chefe desempregado buscam emprego no mercado de trabalho e, no caso de sucesso, um novo rendimento familiar passa a ser auferido; (iv) o demandante de trabalho demite chefes de domicílio, até equilibrar o mercado de trabalho; (v) os domicílios usuários dos aplicativos de informações reduzem suas despesas; (vi) os provedores periodicamente inovam, conforme seus in-

\footnotetext{
${ }^{20} \mathrm{~A}$ heterogeneidade dos domicílios foi configurada de forma a reproduzir a distribuição real dos domicílios na faixa socioeconômica em questão, a partir dos dados da PNAD (Pesquisa Nacional por Amostras de Domicílios) (IBGE, 2013), em particular para as variáveis qualificação profissional (a partir dos anos de escolaridade do chefe do domicílio, como proxy), renda domiciliar mensal e situação de emprego (ocupação).

${ }^{21} \mathrm{~A}$ demanda por trabalho foi configurada a partir dos dados empíricos disponíveis para as principais áreas metropolitanas na PED (Pesquisa de Emprego e Desemprego) (DIEESE, 2013).

${ }^{22} \mathrm{O}$ modelo conta ainda com equações auxiliares, desdobramentos "mecânicos" das equações principais como, por exemplo, contadores e acumuladores, identidades contábeis, geração de estatísticas etc.

${ }^{23}$ Para compatibilizar o modelo com os dados empíricos disponíveis na PNAD (IBGE, 2013), apenas a situação de emprego do chefe do domicílio ("pessoa de referência") é modelada. Isso certamente subestima o impacto dos benefícios indiretos do domicílio, uma vez que os demais moradores também podem auferi-los.
} 
vestimentos em P\&D, e elevam a qualidade de seus aplicativos; (vii) conforme angariam do micílios usuários, os provedores auferem receitas e alocam parcela destas para investir em P\&D.

A implantação do sistema TVDI nos domicílios foi modelada em duas etapas. A primeira, considerando-se o cronograma oficial de desligamento da TVA nos 564 municípios que compõem as 35 principais regiões urbanas brasileiras (MINICOM, 2015). A segunda, projetando-se o mesmo ritmo de implantação da primeira etapa ${ }^{24}$ para todos os demais municípios envolvidos ${ }^{25}$. Um parâmetro importante para a definição do processo de difusão, desconhecido a priori, é fração final (maxAdoc $\left.{ }^{26}\right)$ de domicílios que efetivamente disporá do STB com interatividade completa habilitada, uma vez que nem todos os domicílios inicialmente aptos a receber o STB dentro do programa governamental (cerca de 10 milhões de famílias segundo a PNAD 2013) efetivamente se tornarão usuários da TVDI. Dois cenários serão propostos, configurando alternativas extremas de política governamental.

A escolha do provedor de informação pelo domicílio $i$ que dispõe de STB com interatividade acontece a cada três períodos (meses). É suposto, de forma simplificada, que cada domicílio adota apenas um aplicativo a cada período. A escolha será, então, entre manter o provedor atual, caso a qualidade média do aplicativo deste seja igual ou superior à média do mercado de aplicativos, ou adotar o provedor que oferece o melhor aplicativo naquele momento, caso contrário. A qualidade do aplicativo do provedor $j$ no períodot $\left(Q u a l A p l l_{j}^{t}\right)$ é uma grandeza definida entre 0 e 1 , com 0 representando a qualidade mínima e 1 a máxima.

No modelo, o chefe de cada domicílio $i$ conta com certo nível de qualificação profissional (QualProf $f_{i}^{t}$ ) a cada time step $t$. A proxy adotada para a qualificação profissional é a escolaridade, medida em anos de estudo. À semelhança da metodologia empregada pelo IBGE (2013), QualProf $f_{i}^{t}$ pode variar entre 0 (zero ano de estudo) e 1 (15 ou mais anos de estudo), linearmente. Ceteris paribus, no modelo a única forma de incremento da qualificação profissional durante $t$, de cada domicílio $i\left(\Delta Q\right.$ ualProf $_{i}^{t}$ ), é a utilização de um aplicativo TVDI adequado:

$$
\Delta \text { QualProf }_{i}^{t}=\left\{\begin{array}{lr}
0, & \text { if } u s a A p l Q u a l_{i}=0 \text { or } \text { Empr }_{i}^{t}=1 \\
t x_{\text {Qual }} Q u a l A p l D o m_{i}^{t}, & \text { caso contrário }
\end{array}\right.
$$

O parâmetro txQual é uma constante que indica o quanto o uso do aplicativo de qualificação profissional pode incrementar a qualificação e QualAplDom $i_{i}^{t}$ representa a qualidade corrente (no tempo $t$ ) do aplicativo selecionado pelo domicílio $i$. Dado o tempo necessário para a qualificação, o incremento somente acontece quando o chefe do domicílio $i$ está desempregado $\left(E m p r_{i}^{t}=0\right)$ e é efetivamente usuário do aplicativo de qualificação ( $\left.u s a A p l Q u a l_{i}=1\right)^{27}$.

A probabilidade de um chefe de domicílio desempregado encontrar trabalho foi modelada a partir dos parâmetros $\left(d_{0}\right.$ e $d_{\text {Qual }}$ ) estimados por uma regressão tipo logit sobre dados empíricos selecionados da PNAD $^{28}$ (IBGE, 2013), ajustada para o segmento de domicílios em questão. Os detalhes econométricos estão apresentados no Apêndice. Como o único parâmetro heterogêneo do

\footnotetext{
${ }^{24}$ A primeira etapa de implantação aponta para um crescimento razoavelmente linear $\left(R^{2}=0,97\right)$ do número de domicílios do Programa Bolsa Família atendidos pela TVD.

${ }^{25}$ Essa é uma premissa conservadora, pois, apesar de não prever cronograma específico, a Portaria 2765 de 08/07/2015 (MINICOM, 2015) estipula que todas as "cidades não listadas [na primeira etapa]" devem ter a migração para a TVD realizada em 25/11/2018.

${ }^{26} \mathrm{~A}$ descrição da nomenclatura das variáveis e parâmetros encontra-se no Apêndice.

${ }^{27}$ A distribuição do uso do aplicativo respeita a distribuição empiricamente verificada no projeto piloto de João Pessoa (CASTILLEJO, 2013).

${ }^{28}$ Variáveis explicativas: escolaridade, idade, sexo, cor e situação censitária. Todas as variáveis são estatisticamente relevantes. O modelo logit proposto explica 68,8\% das observações de desemprego.
} 
modelo econométrico que está modelado é a qualificação profissional (QualProf), a probabilidade de emprego pode ser simplificada ${ }^{29}$ como:

$$
\operatorname{Pr}\left(\operatorname{Empr}_{i}^{t}=1\right)=1-\frac{1}{1+e^{d_{0}+d_{\text {Qual QualProf }}{ }_{i}^{t-1}}}
$$

O nível médio de emprego da população é avaliado a partir da mesma equação, considerando a qualificação média da população como um todo, a cada período. Dessa forma o mercado de trabalho se ajusta até atingir a taxa de emprego esperada para cada período $t$, pelo movimento de demissões pelo demandante de trabalho, conforme o nível geral de qualificação - aqui, como proxy da produtividade do trabalho.

Definida a situação de emprego do chefe do domicílio, a renda domiciliar (RendDom $\left.{ }_{i}^{t}\right)$ também é modelada a partir dos dados empíricos da PNAD (IBGE, 2013), por meio de uma regressão dos atributos usuais ${ }^{30}$ sobre o logaritmo da renda domiciliar. Os detalhes econométricos estão no Apêndice. Com os parâmetros obtidos, tomando em conta apenas a dimensão qualificação, podemos ajustar uma equação de rendimento domiciliar simplificada ${ }^{31}$ (parâmetros $r_{0}$ e $r_{Q u a l}$ ) para o segmento de domicílios do PBF:

$$
\operatorname{RendDom}_{i}^{t}= \begin{cases}\max \left(\sim \operatorname{normal}\left[\operatorname{rend}_{\text {Des }}, S_{\text {Rend }}\right], 0\right), & \text { if } \operatorname{Empr}_{i}^{t}=0 \\ \operatorname{RendDom}_{i}^{t-1}+\left(e^{r_{0}+r_{\text {Qual QualProf }}^{t}}-e^{\left.r_{0}+r_{\text {Qual QualProf }}{ }_{i}^{t-1}\right)}\right), & \text { if } \text { Empr }_{i}^{t}=1\end{cases}
$$

A renda dos domicílios com chefe de família desempregados $\left(E m p r_{i}^{t}=0\right)$ é determinada a partir da distribuição empírica (média rend $_{\text {Des }}$ e desvio padrão $s_{R e n d}$ ) do rendimento dos domicílios nessa situação (IBGE, 2013). O valor dos benefícios diretos, a economia com informações $\left(E \operatorname{coIn} f_{i}^{t}\right)$ dos domicílios é atualizada a cada período utilizando-se os valores empíricos obtidos no projeto piloto (CASTILLEJO, 2013). ${ }^{32}$

Os processos de inovação e competição entre os provedores de aplicativos seguem os princípios gerais de competição schumpeteriana (NELSON; WINTER, 1982) e não serão detalhados, por bastante similares a modelos anteriores (POSSAS et al., 2001; WINDRUM, 2007). A escolha dos parâmetros críticos do processo inovador $-p_{\text {Inov }}$, probabilidade de inovação por Real gasto em $\mathrm{P} \& \mathrm{D}$, e $S_{\text {Inov }}$, desvio padrão da qualidade dos aplicativos inovadores - foram arbitrariamente ajustados para valores que permitissem um mercado competitivo que produzisse constante melhoria dos aplicativos oferecidos aos domicílios ao longo de 120 períodos (10 anos).

\section{Resultados do modelo}

O objetivo do modelo de simulação proposto não é gerar previsões precisas sobre o futuro, dadas as restrições às quais esse tipo de modelo está submetido (LAWSON, 1997). Seu principal objetivo é, por outro lado, testar se o conjunto de hipóteses, associado com a explicação um dado fenômeno econômico, é logicamente compatível com os fatos estilizados provenientes da análise empírica. Em termos mais gerais, o modelo de simulação deve facilitar a avaliação, a comparação e a combinação de ideias e hipóteses - incluindo relações de causalidade entre as variáveis relevantes - ao mesmo tempo em que permanece (ou não) compatível com os fatos estilizados mais importan-

\footnotetext{
${ }^{29}$ Supondo as demais variáveis mantidas iguais às suas médias.

${ }^{30}$ Variáveis explicativas: escolaridade, idade, horas trabalhadas (log), sexo, cor, posição e situação censitária. Todas as variáveis são estatisticamente relevantes. O coeficiente de determinação do modelo é $R^{2}=0,37$.

${ }^{31}$ Supondo as demais variáveis mantidas iguais às suas médias.

${ }^{32}$ Todos os valores foram atualizados para a base de junho de 2015 pelo INPC.
} 
tes (PYKA; FAGIOLO, 2005). Além disso, o modelo de simulação costuma produzir resultados que não são fácil ou diretamente deriváveis da teoria que os suporta, permitindo a melhor compreensão de mecanismos causais em sistemas econômicos complexos (PRADO, 2009).

O modelo proposto foi configurado a partir de um quadro teórico relativamente consolidado, conforme apresentado na Seção 2, e calibrado, majoritariamente, com parâmetros provenientes da análise empírica (detalhes no Apêndice). Isso reduz o número de graus de liberdade do sistema de simulação e simplifica o processo de análise dos seus resultados, dado o restrito número de parâmetros escolhidos de forma "arbitrária". ${ }^{33}$ Um desses parâmetros representa, justamente, as escolhas dos gestores de políticas públicas para a TVDI, justamente a fração máxima do conjunto de domicílios alvo até a qual o programa irá se expandir $(\max A d o c)$.

Considerado 10,25 milhões de domicílios como limite superior para o projeto de $\mathrm{TVDI}^{34}$, dois cenários de política pública são propostos, conforme a Tabela 1. O cenário A ("Parcial") significa uma implantação da TVDI atingindo somente uma parcela restrita dos domicílios do PBF (50\%); o cenário B ("Integral") apresenta uma difusão da TVDI alcançando 90\% dos domicílios do PBF.

Tabela 1 - Cenários de simulação (políticas públicas alternativas).

FONTE: análise dos autores.

\begin{tabular}{l|c} 
Cenário & $\max$ Adoc \\
\hline A. Parcial & $\mathbf{5 0 \%}(5,1 \mathrm{M}$ dom. $)$ \\
B. Integral & $\mathbf{9 0 \%}(9,2 \mathrm{M}$ dom. $)$
\end{tabular}

A avaliação dos efeitos econômicos da implantação do projeto de TVDI no conjunto dos domicílios alvo foi realizada por meio do acompanhamento de 5 indicadores durante a simulação: (i) economia com informação, (ii) renda domiciliar, (iii) qualificação profissional, (iv) desemprego e (v) tempo de procura por emprego. O primeiro indicador sintetiza os benefícios diretos do programa, enquanto os demais procuram mensurar o impacto e a grandeza dos benefícios indiretos, foco principal de investigação. Os resultados produzidos pelo modelo estão sumarizados na Tabela 2.

Em linhas gerais os resultados obtidos indicaram variações nas direções (sinais) esperadas. A introdução do STB interativo no domicílio foi positivamente correlacionada com aumento da economia com informação (redução das despesas do domicílio), com a renda domiciliar e a qualificação profissional do chefe do domicílio. Apresentou-se, ainda, negativamente correlacionada com o tempo de procura de emprego. O impacto sobre a taxa de desemprego é dúbio, porém com valores muito pequenos. Nem todos os resultados apresentaram diferenças estatisticamente significativas entre os dois grupos de domicílios analisados (com ou sem STB/TVDI). Esse é o caso do tempo de procura de emprego, no cenário "Parcial", e da taxa de desemprego, nos dois cenários.

Tabela 2 - Sumário dos resultados do modelo (final do período de 200 meses de avaliação).

\footnotetext{
${ }^{33}$ Os 4 parâmetros que não são diretamente oriundos da análise empírica, podem ser classificados em dois grupos: parâmetros de configuração do processo de inovação e competição (3) e o parâmetro que define a meta da política de implantação do sistema TVDI. O primeiro grupo adotou premissas usuais de modelos de competição em setores tecnologicamente dinâmicos (WINDRUM, 2007). O segundo, simplesmente, avaliou cenários que representam políticas governamentais distintas.

${ }^{34}$ Esse número representa o total de domicílios brasileiros considerados como potenciais participantes do PBF, no caso aqueles com renda per capita igual ou inferior a $\mathrm{R} \$ 192,00$ e que dispunham de aparelho de televisão em cores, conforme a PNAD 2013 (IBGE, 2013) com valores atualizados para junho de 2015. Esse valor corresponde ao teto da renda para participação no PBF mais o valor máximo do benefício per capita do programa.
} 


\begin{tabular}{|c|c|c|c|c|c|c|c|c|}
\hline \multirow{2}{*}{$\begin{array}{r}\text { Cenário } \\
\text { Domicílios }\end{array}$} & \multicolumn{4}{|c|}{ Parcial } & \multicolumn{4}{|c|}{ Integral } \\
\hline & $s / S T B$ & $c / S T B$ & $\Delta$ & $\Delta \%$ & $s / S T B$ & $c / S T B$ & $\Delta$ & $\Delta \%$ \\
\hline Economia mensal média com informação ( $R \$$ ) & 0 & 0,81 & $+0,81 * * *$ & & 0 & 0,80 & $+0,80 * * *$ & \\
\hline Renda domiciliar mensal (R\$) & 623,00 & 674,70 & $+51,70 * * *$ & $+8,3 \%$ & 620,70 & 666,70 & $+46,00 * * *$ & $+7,4 \%$ \\
\hline Qualificação profissional chefe (anos de estudo) & 4,27 & 5,44 & $+1,17 * * *$ & $+27,4 \%$ & 4,26 & 5,32 & $+1,05 * * *$ & $+24,7 \%$ \\
\hline Taxa de desemprego médio & $13,55 \%$ & $13,53 \%$ & $-0,0002$ & $-0,15 \%$ & $13,62 \%$ & $13,65 \%$ & $+0,0003$ & $+0,22 \%$ \\
\hline Tempo de procura de emprego médio (meses) & 9,63 & 9,61 & $-0,016$ & $-0,17 \%$ & 9,60 & 9,58 & $-0,016 * *$ & $-0,17 \%$ \\
\hline
\end{tabular}

** $\mathrm{e}^{* * *}$ indicam significância ao nível de $5 \%$ e $1 \%$, respectivamente, na comparação entre as médias dos grupos de domicílios.

FONTE: análise dos autores.

A taxa de desemprego médio (ao longo de 200 meses) manteve-se essencialmente inalterada, nos dois grupos de domicílios, durante toda a simulação. Esse resultado é, em princípio, surpreendente, dado que a configuração do modelo altera a probabilidade de emprego dos chefes de domicílio conforme estes aumentam sua qualificação, a partir do modelo econométrico baseado em dados reais (Apêndice). A análise detalhada mostrou que isso se deveu à ausência de crescimento na demanda de trabalho simulada (exógena).

Chama a atenção, ainda, o valor modesto dos efeitos econômicos individuais para os domicílios do grupo que recebeu STB interativo. A economia com informação se mostrou restrita, representando algo em torno de $0,1 \%$ da renda familiar do segmento de domicílios em questão. $\mathrm{O}$ aumento da renda, apesar de mais importante (cerca de 8\%), ocorreu em um período longo (200 meses), sendo provavelmente pouco relevante face ao valor acumulado esperado de outros fatores que costumam afetar a renda (crescimento econômico, dinâmica do mercado de trabalho, inflação). A redução do tempo médio de desemprego (cerca de 0,2\%) também não teve impacto marcante, dada a relativa infrequência da alternância entre períodos de emprego e desemprego ${ }^{35}$. Uma consequência direta dessas constatações é a confirmação da provável inviabilidade do projeto sem subsídios governamentais.

Outra característica interessante dos resultados do modelo é a relativa insensibilidade dos resultados obtidos face às importantes diferenças entre os dois cenários. De forma talvez não surpreendente, a dinâmica de introdução do projeto não afetou de forma significativa os mecanismos acionados nos domicílios a partir da instalação da STB. A dinâmica "macro" dentro do segmento dos domicílios analisados foi dominada, essencialmente, pela proporção dos domicílios entre os grupos com e sem STB. Isso indica que, provavelmente, o gestor governamental desse tipo de projeto disponha de razoável latitude para escolher a forma de implantação mais adequada, sem que isso afete os benefícios individuais do programa.

Resta ainda avaliar os efeitos econômicos "macro" do projeto TVDI. Nesse caso, obviamente, a dinâmica agregada de implantação do projeto tem impactos relevantes sobre o nível de bem-estar social produzido. A Tabela 3 apresenta um balanço hipotético da execução dos dois cenários avaliados. Na tabela, os resultados associados às linhas da rubrica "Benefícios sociais" foram diretamente produzidos pelo modelo de simulação. Os resultados da rubrica "Despesas governo" pressupõem valores aproximados para cada item, de acordo com a informação disponível ${ }^{36}$. Os resultados são bastante influenciados pelo número de anos adotado na avaliação, dada a presença de custos fixos

\footnotetext{
${ }^{35}$ Isso porque o tempo médio de emprego, para o segmento de trabalhadores analisado, é de mais de 31 meses (DIEESE, 2013).

${ }^{36}$ Foram considerados os seguintes custos, necessários à implantação do projeto de forma subsidiada pelo governo: (i) custo do modem para o canal de retorno de R\$ 50,00, (ii) custo plataforma nacional de TVDI de R\$ 771 milhões e (iii) custo de operação da plataforma nacional de TVDI de R\$178 milhões por ano (valores atualizados levantados em CASTILLEJO, 2013). As premissas sobre subsídio aos provedores de aplicativos estão apresentadas no Apêndice.
} 
(implantação da plataforma nacional e subsídio do modem) e de cumulatividade nos ganhos associados ao aumento da qualificação profissional.

Tabela 3 - Balanço de implantação do projeto TVDI (dois cenários).

\begin{tabular}{|c|c|c|c|c|c|}
\hline \multirow{2}{*}{ (R\$ mil) } & \multirow{2}{*}{$\begin{array}{r}\text { Cenário } \\
\text { Período de avaliação }\end{array}$} & \multicolumn{2}{|c|}{ Parcial } & \multicolumn{2}{|c|}{ Integral } \\
\hline & & 100 meses & 200 meses & 100 meses & 200 meses \\
\hline \multirow{5}{*}{$\begin{array}{c}\text { Despesas } \\
\text { governo }\end{array}$} & Implantação plataforma nacional & 771.378 & 771.378 & 771.378 & 771.378 \\
\hline & Manutenção plataforma nacional & 1.483 .418 & 2.966 .837 & 1.483 .418 & 2.966 .837 \\
\hline & Subsídio modem domicílios & 256.300 & 256.300 & 461.340 & 461.340 \\
\hline & Subsídio provedores de aplicativos & 71.220 & 142.440 & 71.220 & 142.440 \\
\hline & Total & 2.582 .316 & 4.136 .954 & 2.787 .356 & 4.341.994 \\
\hline \multirow{4}{*}{$\begin{array}{l}\text { Benefícios } \\
\text { sociais }\end{array}$} & Economia com informação & 601.750 & 1.203 .500 & 945.833 & 1.891 .667 \\
\hline & Aumento renda domiciliar & 9.893 .180 & 53.002 .840 & 15.777 .828 & 84.886 .560 \\
\hline & Redução tempo procura emprego & 61.742 & 137.500 & 75.950 & 214.041 \\
\hline & Total & 10.556 .672 & 54.343 .840 & 16.799.611 & 86.992.267 \\
\hline \multirow{2}{*}{$\begin{array}{l}\text { Balanço bem- } \\
\text { estar social }\end{array}$} & Resultado líquido & +7.974 .356 & +50.206 .885 & +14.012 .255 & +82.650 .273 \\
\hline & Retorno sobre despesa & $+309 \%$ & $+1214 \%$ & $+503 \%$ & $+1904 \%$ \\
\hline
\end{tabular}

FONTE: análise dos autores.

O resultado social agregado é inequivocamente positivo para qualquer dos cenários abordados. Entretanto, o excedente do bem-estar social é claramente superior conforme mais domicílios são agregados ao programa, como no cenário "Integral". Rodadas de simulação alternativas, adicionais às apresentadas, confirmam a hipótese de que a extensão da cobertura do projeto domina a velocidade de implantação, quando a métrica de avaliação do projeto é o retorno social sobre a despesa governamental. Isso se dá porque a maior parte dos custos do projeto TVDI está associada com a implantação e manutenção da plataforma nacional de suporte, que são razoavelmente insensíveis ao número de usuários, ao passo que, como já visto, os benefícios sociais escalam de forma essencialmente proporcional ao número de domicílios participantes.

\section{Conclusão}

Os resultados obtidos pelo modelo estão, em termos qualitativos, alinhados com os fatos estilizados usualmente associados com programas de inclusão digital para segmentos de baixa renda. Ou seja, aceitando-se as premissas teóricas apresentadas, o projeto inovador de TVDI para os beneficiários do programa Bolsa Família, em princípio, deve produzir efeitos no sentido de aumentar a renda disponível dos domicílios atendidos. Como visto, esse aumento se origina tanto de forma direta, pela redução dos custos associados com a obtenção de informações indispensáveis para as famílias, como indireta, pelo aumento do nível de qualificação profissional e a consequente elevação da renda oriunda do trabalho.

Entretanto, em termos quantitativos, a dimensão dos benefícios produzidos foi modesta, no âmbito do domicílio individual. Seja pela demanda relativamente limitada de informação demandada pelas famílias, nesse estrato socioeconômico, seja pelo tempo relativamente escasso de que dispõem os chefes de domicílio para participar de programas de qualificação - considerando a magnitude dos períodos requeridos para um aumento significativo da escolaridade - os resultados indicaram as limitações deste tipo de política de inclusão. Claramente, não parece ser possível superar as 
condições de restrição de rendimentos que os beneficiários do programa Bolsa Família estão sujeitos tão somente por meio da inclusão digital.

Por outro lado, a avaliação macroscópica de uma inovação como a TVDI inclusiva deixa evidente seu relevante potencial enquanto estratégia, ainda que complementar, dentro de um conjunto mais amplo de políticas públicas que visem a superação da pobreza. Em particular se considerarmos o potencial, não adequadamente explorado pelo modelo, da utilização plena da TVDI pelas crianças e jovens dos domicílios beneficiados pelo programa. Isso porque, dentre outros fatores, ao disporem de quantidade maior de tempo disponível, crianças e jovens podem usufruir de forma integral os benefícios oferecidos pelas TICs, seja como suporte às atividades escolares já empreendidas de forma convencional, seja no processo de aumento da escolaridade e da qualificação profissional.

\section{Referências bibliográficas}

ALBUQUERQUE E.; CASSIOLATO, J. (2002). As Especificidades do Sistema de Inovação do Setor Saúde. In: Revista de Economia Política, vol. 22, no 4 (88), outubro-dezembro.

AXELROD, R.; TESFATSION, L. (2006). A Guide for Newcomers to Agent-Based Modeling in the Social Sciences. In TESFATSION, L.; JUDD K. (Ed.). Handbook of Computational Economics, Vol. 2: Agent-Based Computational Economics. Amsterdam: North-Holland.

BANCO MUNDIAL (1995). Relatório para o Desenvolvimento mundial 1995: o trabalhador e o processo de integração mundial, 1 ed. Washington: Banco Mundial, p. 11-132.

(1995). Reformas Econômicas e Trabalhistas na América Latina e no Caribe. Disponível em: http://www-

wds.worldbank.org/external/default/WDSContentServer/WDSP/IB/2005/10/03/000011823_20051003 155338/Rendered/PDF/14922010portuguese.pdf.

CASTILlEJO, A. G. (Org.) (2013). Socio-Economic Impact Study. In Brazilian National Digital Public Broadcasting Network Operator (RNRPD) - Banco Mundial/LAC, Gobierno de España; Empresa Brasil de Comunicação. No prelo.

CASTRO, J. A. (2012). Política social e desenvolvimento no Brasil. In: Revista Economia e Sociedade, Campinas, v. 21, Número Especial, p. 1011-1042.

CEPAL (2012). Structural Change For Equality - An Integrated Approach to Development. Thirty-fourth Session of ECLAC. San Salvador

CIMOLI, M. (Ed.) (2005). Heterogeneidad estructural, asimetrías tecnológicas y crecimiento en América Latina. Santiago de Chile: CEPAL.

COASE, R. (1937). The Nature of the Firm. Economica, nouveles series, v. 4.

COLANDER, D. (2005).The future of economics: the appropriately educated in pursuit of the knowable. Cambridge Journal of Economics, Oxford, v. 29, n. 6, p. 927-941, Nov. 2005.

Departamento Intersindical de Estatística e Estudos Socioeconômicos (DIEESE) (2013). Pesquisa de Emprego e Desemprego - PED Metropolitana 2013. Disponível em: http://www.dieese.org.br/analiseped/2013/2013microdadospedmet.zip. Página visitada em 25/06/2015.

EVANS, D. (2011). Platform Economics: Essays on Multi-Sided Businesses. Competition Policy International. Disponível em: http://ssrn.com/abstract=1974020.

FAGNANI, E. (2014). Política social e desigualdade: projetos em disputa. Texto para Discussão No 238. Intituto de Economia. UNICAMP, Campinas

(2005). Política Social no Brasil (1964 - 2002): Entre a Cidadania e Caridade. Tese de Doutoramento. IE/UNICAMP. 
HARLVONSEN, J. K.; MILES, I; ROSTE, R. (2005). On the differences between public and private sector innovation. European Commission, PUBLIN Research Project. Oslo.

HOLANDA, G. (2007). TICs: tendências, visão holística e P\&D. CPqD. Apresentação no IPEA/DISET. Dezembro.

INNO GRIPS (2010). Innovation - Grips (Global Review of Innovation Public Policy Studies). European Commission project. Three year cycle (February 2010- January 2013).

Instituto Brasileiro de Geografia e Estatística (IBGE) (2013). Pesquisa Nacional por Amostras de Domicílios - PNAD 2013. Disponível em: ftp://ftp.ibge.gov.br/Trabalho_e_Rendimento/ Pesquisa_Nacional_por_Amostra_de_Domicilios_anual/microdados/2013/Dados.zip. Página visitada em 25/06/2015.

KATZ, R. (2009). The Economic and Social Impact of Telecommunications Output: A Theoretical Framework and Empirical Evidence for Spain. Intereconomics, January/February 2009, p. 41-48.

LAWSON, T. (1997). Economics and reality. London: Routledge.

MALERBA, F.; ORSENIGO, L. (2000). Knowledge, Innovative Activities and Industrial Evolution. Industrial and Corporate Change, Oxford, v. 9, n. 2, p. 289-314.

MEDEIROS, C. (2015). Inserção Externa, Crescimento e Padrões de Consumo na Economia Brasileira. IPEA, Brasília, 2015.

MINISTÉRIO DAS COMUNICAÇÕES (MINICOM) (2015). Portaria número 2765 de 08/07/2015. (2014). Portaria número 481 de 09/07/2014.

MULGAN, G.; ALBURY D. (2003). Innovation in the Public Sector. Strategy Unity, Cabinet Office. United Kingdom.

NELSON, R. R.; WINTER, S. G. (1982). Uma teoria evolucionária da mudança econômica. Trad. C. Heller. Campinas: Ed. UNICAMP, 2005.

POSSAS, M. L.; KOBLITZ, A.; LICHA, A.; OREIRO, J. L.; DWECK, E. (2001). Um Modelo Evolucionário Setorial. Revista Brasileira de Economia, Rio de Janeiro, v. 55, n.3, p. 333-377, jul./set. 2001.

PRADO, E. F. S. (2009). Economia, complexidade e dialética. São Paulo: Pleiade.

PricewaterhouseCoopers (PWC) (2008). How to capture value through software R\&D. Disponível em: http://www.pwc.com/us/en/technology-innovation-center/assets/softwarerandd.pdf. Página visitada em 05/07/2013.

PYKA, A.; FAGIOLO, G. (2005). Agent-Based Modelling: A Methodology for Neo-Schumpeterian Economics. Working Paper n. 272, Institut for Volkswirtschaftslehre, Universitaet Augsburg.

RAUSSER, G., SWINNEN, J.; ZUSMAN, P. (2011). Political Power and Economic Policy - Theory, Analysis and Empirical Applications. Cambridge University Press. New York

SORAYA, B. e BRUNO-FARIA, M.F. (2013). Inovação no setor público: análise da produção científica em periódicos nacionais e internacionais da área de administração. In: Rev. Adm. Pública — Rio de Janeiro 47(1):227-248, jan./fev. 2013

Universo OnLine (UOL) (2013). Tabela de preços para clientes ativos - jul. 2013. Disponível em: http://download.uol.com.br/publicidade/Publicidade.pdf. Página visitada em 05/07/2013.

VIANA, A.; SILVA, H. (2010). Avaliando a difusão de tecnologias médicas no sistema de saúde privado no Brasil: o caso da tomografia por emissão de pósitrons (PET).In: Rev. Bras. SaúdeMatern. Infant., Recife, 10 (Supl. 1): S187-S200 nov.

WINDRUM, P. (2007). Neo-Schumpeterian simulation models. In HANUSCH, H.; PYKA, A. (Ed.). Elgar Companion to Neo-Schumpeterian Economics. Cheltenham: Edward Elgar, p. 405-439. 


\section{Apêndice - Configuração do Modelo de Simulação Agent-based}

Plataforma de desenvolvimento: C++/LSD 6.4 (labsimdev.org)

Formato de modelagem: equações em diferenças / tempo discreto (simulação time-driven)

Temporalidade da simulação:

Time step (unidade): mês Período de tempo simulado: 200 meses

Número de rodadas (amostras) para avaliação dos resultados: 100

Precisão mínima da estimação dos resultados: $\pm 5 \%$ com nível de confiança de $95 \%$

Agentes modelados: domicílios e provedores de aplicativos

Número de objetos (agentes modelados):

Domicílio: 10.252 (PNAD 2013)

Provedor: 6 (arbitrário)

Variáveis de estado modeladas:

$\begin{array}{lllll}\text { Domicílios (i) } & & & \\ \text { Nome } & \text { Descrição } & \text { Unidade / métrica } & \text { Lags } & \text { Cond. inicial } \\ \text { STB } & \text { Presença de STB } & \text { 1: sim / 0: não } & 1 & 0 \\ \text { MesSTB } & \text { Tempo com STB } & \text { meses } & 1 & 0 \\ \text { ProvApl } & \text { Provedor de aplicativo selecionado } & \text { Id. do provedor } & 1 & -1 \text { (sem prov.) } \\ \text { QualProf } & \text { Qualificação profissional } & \text { 0 a 1 (1 a 15 anos) } & 1 & 0 \\ \text { Empr } & \text { Situação de emprego } & \text { 1: empreg. / 0: des. } & 1 & 0 \\ \text { MesSitEmpr } & \text { Tempo na situação atual de emprego } & \text { meses } & 1 & 0 \\ \text { RendDom } & \text { Rendimento domiciliar mensal } & \text { Reais } & 1 & 0 \\ \text { Ecolnf } & \text { Economia com informação mensal } & \text { Reais } & 0 & \\ \text { Provedores (j) } & & & & \\ \text { Nome } & \text { Descrição } & \text { Unidade / métrica } & \text { Lags } & \text { Cond. inicial } \\ \text { QualApl } & \text { Qualidade do aplicativo } & 0 \text { a 1 (1: melhor) } & 1 & \sim \text { unif(0; 0,2) } \\ \text { MktShr } & \text { Market share do aplicativo } & 0 \text { a 1 } & 1 & 0 \\ \text { Inov } & \text { Ocorrência de inovação no período } & 1: \text { sim / 0: não } & 0 & \\ \text { DespPDAcum } & \text { Despesa P\&D acumulada desde inov. } & \text { mil Reais } & 1 & 0 \\ \text { RecGov } & \text { Receita subsídio govern. no período } & \text { mil Reais } & 0 & \\ \text { RecPub } & \text { Receita com publicidade no período } & \text { mil Reais } & 0 & \end{array}$

Parâmetros do modelo:

$\begin{array}{llll}\text { Nome } & \text { Descrição } & \text { Valor } & \text { Fonte } \\ \text { txQual } & \text { Taxa de aumento mensal máxima da qualificação } & 0,005556 & \text { PNAD 2013 } \\ \text { pAplQual } & \text { Probabilidade de uso do aplicativo de qualificação } & 0,65 & \text { Piloto 2013 } \\ \text { tProcMed } & \text { Tempo médio de procura de emprego } & 8,551 \text { meses } & \text { PED 2013 } \\ \text { tProcDP } & \text { Desvio padrão do tempo médio procura emprego } & 13,81 \text { meses } & \text { PED 2013 } \\ \text { desEsp0 } & \text { Desemprego inicial } & 0.1350 & \text { PNAD 2013 } \\ \text { d0 } & \text { Intercepto modelo desemprego (ver abaixo) } & 2,243 & \text { PNAD 2013 } \\ \text { dQual } & \text { Peso da qualificação modelo desemprego (abaixo) } & -1,293 & \text { PNAD 2013 } \\ \text { r0 } & \text { Intercepto modelo renda domiciliar (ver abaixo) } & 6,097 & \text { PNAD 2013 } \\ \text { rQual } & \text { Peso da qualificação modelo renda domiciliar (ab.) } & 1,177 & \text { PNAD 2013 } \\ \text { sRend } & \text { Desvio padrão da renda domiciliar mensal } & \text { R\$ 332,04 } & \text { PNAD 2013 } \\ \text { rendDes } & \text { Renda mensal média dos domicílios c/ desemprego } & \text { R\$ 373,72 } & \text { PNAD 2013 } \\ \text { pAplInf } & \text { Probabilidade de uso aplicativo informações sociais } & 0,73 & \text { Piloto 2013 } \\ \text { cDesl } & \text { Custo médio do deslocamento urbano (evento) } & \text { R\$ 5,46 } & \text { Piloto 2013 }\end{array}$




$\begin{array}{llll}\text { cTel } & \text { Custo médio informação telefônica (evento) } & \mathrm{R} \$ 2,37 & \text { Piloto } 2013 \\ \text { cOpTrab } & \text { Custo oportunidadetrabalhadores empregados (h) } & \mathrm{R} \$ 4,75 & \text { Piloto 2013 } \\ \text { tInfQual } & \text { Tempo médio entre buscasinfo. qualificação prof. } & 1 \text { mês } & \text { Piloto 2013 } \\ \text { tInfSoc } & \text { Tempo médio entre buscasinfo. benefícios sociais } & 24 \text { meses } & \text { Piloto 2013 } \\ \text { plnov } & \text { Probabilidade de inovação por R\$ gasto em P\&D } & 404 & \text { arbitrário } \\ \text { slnov } & \text { Desvio padrão da qualidade aplicativosinovadores } & 0,04 & \text { arbitrário } \\ \text { c0 } & \text { Despesa inicial P\&D com novos aplicativos (12 meses) } & \text { R\$ 71,2 mil } & \text { Piloto 2013 } \\ \text { cFix } & \text { Despesa mensal fixa em P\&D (>12 meses) } & \mathrm{R} \$ 47,5 \text { mil } & \text { Piloto 2013 } \\ \text { cVar } & \text { Parcela receita aplicada em P\&D (>12 meses) } & 0,167 & \text { PWC 2008 } \\ \text { subs } & \text { Subsídio governamental mensal (fixo) } & \mathrm{R} \$ 118.7 \text { mil } & \text { Piloto 2013 } \\ \text { recDom } & \text { Receita publicitária por domicílio } & \mathrm{R} \$ 0,101 & \text { UOL 2013 } \\ \text { shrMin } & \text { Market share mínimo para viabilizar publicidade } & 0,10 & \text { arbitrário } \\ \text { txAdoc } & \text { Inclinação da tendência de domicílios com STB (lin.) } & 0,009158 & \text { MC 2015 } \\ \text { iniAdoc } & \text { Intercepto da tendência de domicílios com STB (lin.) } & -0,0070518 & \text { MC 2015 } \\ \text { maxAdoc } & \text { Fração máxima dos domicílios com STB } & \text { cf. cenário } & \text { arbitrário }\end{array}$

Fontes de informação para calibração dos parâmetros

PNAD 2013 Pesquisa Nacional por Amostra de Domicílios 2013 (IBGE, 2013)

PED 2013 Pesquisa de Emprego e Desemprego 2013 (DIEESE, 2013)

Piloto 2013 Projeto-piloto TVDI de João Pessoa (CASTILLEJO, 2013)

PWC 2008 How to capture value through software R\&D (PWC, 2008)

UOL 2013 Tabela de preços para clientes ativos, jul. 2013 (UOL, 2013)

MC 2015 Portaria do Ministério das Comunicações (MINICOM, 2015)

arbitrário Selecionado pelo modelista conforme justificado no texto

Modelos econométricos utilizados no modelo:

\section{Desemprego}

Tipo: regressão logit

Base de dados: microdados PNAD 2013

Seleção amostra: pessoa de referência domicílio

Número de observações: 78.159

Variável explicada: probabilidade estar ocupado

Variável explicativa principal: escolaridade (anos de estudo)

Variáveis explicativas de controle: sexo, idade, cor, situação censitária

Modelo:

\begin{tabular}{lcr}
\multicolumn{1}{c}{$X_{i}$} & $\beta_{i}$ & p-valor \\
intercepto & 1,2229 & $<0,0001$ \\
escolaridade (anos) & 0,0510 & $<0,0001$ \\
idade (anos/10) $^{2}$ idade $\left((\text { anos } / 10)^{2}\right)$ & 0,7761 & $<0,0001$ \\
sexo (feminino) & $-0,0544$ & $<0,0001$ \\
cor (não branco) & $-0,5647$ & $<0,0001$ \\
situação (rural) & $-0,1921$ & $<0,0001$ \\
AIC = 19.859, concordância (prev.-obs.) $=68,8 \%$ & 0,0001
\end{tabular}

$$
\operatorname{logit}\left[\operatorname{Pr}\left(\text { ocupado } \mid X_{i}\right)\right]=\alpha+\beta_{i} X_{i}
$$

Resultados:

\section{Renda domiciliar}

Tipo: regressão linear MQG

Base de dados: microdados PNAD 2013

Seleção amostra: pessoa de referência ocupada

Número de observações: 69.931

Variável explicada: renda domiciliar mensal (log)

Variável explicativa principal: escolaridade (anos de estudo)

Variáveis explicativas de controle: horas trabalhadas, setor atividade, posição no trabalho, sexo, idade, cor, situação censitária (urbano/rural)

Modelo:

Resultados:

$$
\ln (Y D)=\alpha+\beta_{i} X_{i}
$$

\begin{tabular}{lrr}
\multicolumn{1}{c}{$X_{i}$} & \multicolumn{1}{c}{$\beta_{i}$} & \multicolumn{1}{c}{$p$-valor } \\
intercepto & 5,1306 & $<0,0001$ \\
escolaridade (anos) & 0,0785 & $<0,0001$ \\
idade (anos/10) $^{2}$ idade ((anos/10) $^{2}$ ) & 0,2478 & $<0,0001$ \\
horas trabalho (log) & $-0,0064$ & $<0,0001$ \\
sexo (feminino) & 0,2961 & $<0,0001$ \\
cor (não branco) & $-0,1696$ & $<0,0001$ \\
situação (rural) & $-0,2267$ & $<0,0001$ \\
setor (indústria) & $-0,2058$ & $<0,0001$ \\
setor (com./serv.) & 0,1494 & $<0,0001$ \\
posição (serv. pub.) & 0,1575 & $<0,0001$ \\
posição (doméstico) & 0,2781 & $<0,0001$ \\
R $=0,1684$ & $<0,0001$
\end{tabular}

$R^{2}=0,3742$, teste $F=3.216$ ( $p$-valor $<0,0001$ ) 